\title{
Influencia familiar sobre las actitudes ante el consumo de drogas en adolescentes españoles
}

\section{Familiar influence on the attitudes before the consumption of drugs in Spanish teenagers}

\author{
María de la Villa Moral Jiménez ${ }^{1}$ \\ Universidad de Oviedo, España
}

(Recepción: Octubre 2009 - Aceptación: Diciembre 2009)

\begin{abstract}
Resumen
En la cultura mediterránea la familia sigue siendo la agencia socializadora por excelencia, a pesar de diversos cambios referenciales y en la intensidad de los afectos, así como en los estilos disciplinares característicos de nuevas tipologías de familias postmodernas. La influencia y modelado familiar sobre las actitudes ante el consumo de sustancias psicoactivas en adolescentes está bien establecida en indicadores tales como experiencias paternas con las drogas, apego y supervisión parental, clima afectivo, dinámica sociofamiliar, etc. Nuestro objeto de estudio se centra en el análisis psicosocial de tales indicadores, así como en ofrecer un análisis diferencial de la valoración de la relación paterno-filial en relación con las actitudes ante el consumo de drogas en un colectivo de adolescentes españoles. Se ha confirmado una mayor permisividad actitudinal y menor concienciación ante los efectos dañinos de las drogas en los hijos de padres consumidores de sustancias psicoactivas tanto legales como ilegales. Se confirma la importancia psicosocial del Apoyo más valorado por los adolescentes que no consumen drogas, así como la percepción diferencial del empleo del Castigo-Coerción y de la Reprobación en adolescentes consumidores que presentan niveles de mayor permisividad actitudinal.
\end{abstract}

Palabras-Clave: Drogas, Adolescencia, Familia, Intervención psicosocial.

\begin{abstract}
In the Mediterranean culture the family continues being the socialization agency by excellence, in spite of diverse referential changes, in the intensity of the affections and styles you will discipline typical of new typologies of postmodern families. The influence and shaped relative on the attitudes before the consumption of psychoactive substances in teenagers is established well in such indicators as paternal experiences by the drugs, attachment and supervision parental, affective climate, socio familiar dynamics, etc. Our object of study is offer a psychosocial analysis of such indicators, as well as on offering a differential analysis of the valuation of the paternal-affiliated relation linked to the attitudes before the consumption of drugs in a group of Spanish teenagers. A major attitudinal permissiveness before the harmful effects of the drugs in the children of parents consuming psychoactive both legal and illegal substances has been confirmed. It is confirmed the psychosocial importance of the Support most valued by the teenagers who do not consume drugs, as well as the differential perception of the employment of the Punishment-restriction and of the Reproof in consuming teenagers who present levels of major attitudinal permissiveness.
\end{abstract}

Key-Words: Drugs, Adolescence, Family, Psychosocial intervention.

1 Correspondencia: María de la Villa Moral Jiménez. Facultad de Psicología, Universidad de Oviedo, España. Plaza de Feijóo, s/n - despacho 211, 33003 Oviedo (ESPAÑA). Teléfono: (98) 5103282 Fax: (98) 5104144 - (98) 5104141 E-mail: mvilla@uniovi.es 


\section{Introducción teórica}

En los procesos de modelado los padres y los pares se emplean como marcos referenciales, indicativos de pautas de actuación, baluartes de normas reguladoras compartidas, detentadores de valores e impulsores de búsquedas, así como agencias de influencia social normativa, entre otros elementos coadyuvantes. En este sentido, la experimentación juvenil con drogas está determinada por los efectos del modelamiento simbólico, máxime por parte de agencias socializadoras por excelencia como la familia (Martínez, Fuertes, Ramos \& Hernández, 2003) o el propio grupo de iguales (Kloep, Hendry, Ingebrigtsen, Glendinning \& Espness, 2001), como principales baluartes psicosociales de tendencias afiliativas y de los procesos de construcción identitaria. Como referentes actitudinales, los motivadores para el consumo, así como la adquisición de hábitos ligados a semejantes agencias, representan factores ya sea de riesgo o de protección, en función de sus indicadores, de ahí que se abunde en la necesidad de determinar sus procesos de influencia para optimizar los factores protectores e intervenir sobre los de riesgos preventiva y/o rehabilitadoramente.

De acuerdo con los resultados aportados desde la Psicología Social de la Adolescencia la dinámica interaccional de padres e hijos adolescentes no ha de interpretarse como conflictuada, de modo que aun cuando se evidencian discrepancias en la percepción de conflictos y crisis emocionales e identitarias (Moreno, Vacas \& Roa, 2000; Motrico, Fuentes \& Bersabé, 2001; Olmedo, Del Barrio \& Santed, 2000; Rodrigo, Máiquez, Padrón \& García, 2009), principalmente durante la adolescencia media como interrelación con las propias crisis de la sociedad (Moral \& Ovejero, 2004), sin embargo, la satisfacción con la convivencia familiar en un país como España es un indicador inequívoco de un buen ajuste intergeneracional amparado en la prioridad otorgada por los jóvenes españoles a la familia, cuestión ésta evidenciada en diversos informes sociológicos (Alberdi, 1999; Cabrillo, 2004; EUROSTAT, 2000; González, 2000; González-Anleo, 1999; Instituto de Política Familiar, 2008; Moral \& Ovejero, 1998a; Musitu \& García, 2004; Navarro, 2006).

Factores de riesgo de origen familiar vinculados a desregulaciones varias, tales como los concernientes a déficits comunicativos, debilitamiento de apegos, desajustes en las pautas socializadoras o experiencias de modelado, incidirán negativamente sobre las condiciones requeridas para una eficaz acción socioeducativa a nivel actitudinal en materia de drogas. Según lo expuesto en la literatura sobre el tema, no se puede obviar la decisiva acción del modelado paterno sobre la iniciación y mantenimiento del consumo de drogas por parte de sus hijos adolescentes (Barca, Otero, Mirón \& Santorium, 1996; Espada, Pereira \& García-Fernández, 2008; Jennison \& Johnson, 2001; Méndez \& Espada, 1999; Pérez \& Mejía, 1998), a lo cual se ha sumado la constatación del mayor riesgo para aquellos jóvenes procedentes de núcleos familiares donde alguno de sus miembros sea consumidor/dependiente (DiClemente, Wingood, Crosby, Sionean, Cobb, Harrington, Davies, Hook \& Ob, 2001; Muñoz-Rivas \& Graña, 2001; Tarter, Schultz, Kirisci \& Dunn, 2001). De forma general, una actitud familiar permisiva correlaciona con la precocidad del primer consumo alcohólico, además de que la percepción de la propia familia como consumidora se asocia un mayor consumo por parte de los hijos (Rodríguez-Martos, 1996). En consecuencia, se propone que las experiencias paternas con las drogas pueden actuar como acción reforzante directa o vicaria de la iniciación y mantenimiento del consumo (Álvarez, Palacios \& Fuertes, 1999; Barca et al., 1996; Espada et al., 2008; Martínez et al., 2003; Méndez \& Espada, 1999), cuya raigambre es eminentemente psicosocial. La acción del modelado podría calificarse como inductora de actitudes de consumo permisivas, manifestándose una correlación con la precocidad del primer consumo alcohólico en hijos de padres usuarios. En este sentido, la incidencia del alcoholismo paterno como factor de riesgo para el diagnóstico de abuso y dependencia alcohólica también ha sido objeto de estudio en la investigación de Jennison y Johnson (2001). En el sentido contrario, como factor protector podría actuar el denominado modelado prosocial adulto por parte de miembros no consumidores (Sussman, 1995). Desavenencias con las figuras paternas, así como desregulaciones de la dinámica sociofamiliar y déficits comunicacionales, la influencia de la relación afectiva padre-hijo y el manejo familiar se vinculan a la iniciación al consumo (Álvarez et al., 1999; García-Pindado, 1992; Pérez \& Mejía, 1998; Spoth, Redmind \& Lepper, 1999; Vielva, 2001). Respecto al clima afectivo en el hogar, las relaciones negativas entre 
los adolescentes y sus padres y un bajo grado de interacción y de apoyo por parte de éstos aparecen asociados al consumo de drogas (Escámez, 1997), a la par que la disciplina y prácticas educativas paternas pueden actuar como variables moduladoras del consumo de sustancias psicoactivas. Se ha constatado que las acciones de supervisión parental actúan como reguladoras de la percepción de las actitudes y conductas relacionadas con el consumo de sus hijos adolescentes (DiClemente et al., 2001; Martínez et al., 2003; Muñoz-Rivas \& Graña, 2000). Desidentificaciones con las figuras parentales, disconformidades con sus procederes como agentes socializadores u otros conflictos familiares se han considerado como factores de riesgo (Donovan, Jessor \& Costa, 1990; García-Pindado, 1992; Graña \& Muñoz, 2000). Es más, esta tendencia encuentra apoyo en la constatación de que los adolescentes relativamente desvinculados de sus progenitores y que tienden a identificarse más con sus amigos manifiestan tendencias más permisivas respecto al consumo de drogas (Barnea, Teichman \& Rahav, 1992; Moral \& Ovejero, 1998b). Por el contrario, los adolescentes no usuarios de drogas informan de una mayor vinculación a sus progenitores que a sus amigos, tendencia ésta que se invierte en el caso de consumidores (Charro \& Martínez Díaz, 1995). Asimismo, se constata el efecto de un factor de protección asociado al apego familiar y apoyo social percibido (Averna \& Hesselbrock, 2001; Graña \& Muñoz-Rivas, 2000; Martínez \& Robles, 2001).

Con respecto al grupo de iguales, los adolescentes ponen en marcha procesos psicosociales de identificación con el peer-group que contribuyen a la (re)definición de su identidad personal y grupal. Tales procesos y mecanismos de modelado influyen en la iniciación y/o mantenimiento de la experimentación temprana de drogas como el alcohol, tal como hemos comprobado en otros estudios (Moral \& Ovejero, 2003, 2005a, 2005b; Moral, Ovejero, Sirvent, Rodríguez \& Pastor, 2009). La iniciación al consumo se suele producir de la mano de miembros cercanos del grupo de iguales, así la acción de las influencias sociales, y en concreto de amigos consumidores, es un factor predictor de la iniciación al consumo de drogas (Calleja \& Aguilar, 2008; Graña \& Muñoz-Rivas, 2000; JiménezMuro, Belmonte, Marqueta, Gargallo \& Nerón, 2009; Herrero, 2003). Por otro lado, las habilidades de resistencia a la presión grupal son mayores en adolescentes no consumidores de alcohol y tabaco en relación a los consumidores (Andrade, Pérez, Alfaro, Sánchez \& López, 2009; Calleja \& Aguilar, 2008; De Vries, Dijk, Wetzels, Mudde, Kremers, Ariza, et al., 2006; Epstein \& Botvin, 2008; Epstein, Zhou, Bang \& Botvin, 2007; Moral, 2007; Moral et al., 2009).

Nuestro interés investigador se centra en el análisis de variables orécticas, disposicionales y otros indicadores de actitud como factores explicativos del consumo juvenil de sustancias psicoactivas. De este modo, las creencias sobre las consecuencias del consumo y las actitudes hacia el significado social de las propias sustancias se relacionan frecuentemente en la literatura sobre el tema. En este sentido, se constata cómo aquellos individuos que abusan de las drogas tienen unas expectativas diferentes respecto a los probables efectos derivados del empleo de quienes no son consumidores (Novacek, Raskin \& Hogan, 1991), lo cual se asocia a una distorsión de los riesgos derivados de la experimentación (Castellana \& Lladó, 1999; Pascual, 2002). Ello ha de interpretarse aludiendo a que la sensación de invulnerabilidad va asociada a la mentalidad del usuario, como con acierto apuntaron Echeburúa y Del Corral (1988). Mientras los no consumidores valoran negativamente las consecuencias derivadas del consumo e incluso se muestran intolerantes, los usuarios reelaboran creencias falseadas que se adecuan a su necesidad de minimizar los efectos nefastos que provoca el consumo abusivo, al mismo tiempo que valoran con más vehemencia los posibles efectos positivos (desinhibición, euforia, etc.) y los motivadores para su consumo, tales como hedonismo y búsqueda de sensaciones, entre otros, lo cual dependerá de morfotipo de jóvenes consumidores (Sirvent, Moral \& Rodríguez, 2007).

En consecuencia, se propone como objetivo principal de esta aproximación psicosocial a la experimentación juvenil con sustancias psicoactivas analizar las experiencias de consumo paternas, así como incidir sobre los posibles efectos de modelado sobre los patrones de consumo y a nivel actitudinal. De acuerdo a tales presupuestos teóricos, enfrentamientos y apoyos, estilos disciplinares, ajustes o desavenencias con los modelos de referencia y la acción de mecanismos de identificación y rechazo referencial, entre otros indicadores, serán objeto de un análisis descriptivo. Se determinará si la valoración, tanto positiva como negativa, de la relación con los padres varía en los adolescentes 
que experimentan con drogas con respecto a los que no consumen. Según las hipótesis de partida se sostiene que los adolescentes usuarios de sustancias psicoactivas mantendrán unas relaciones más conflictivas y de menor apoyo percibido con sus padres, aun cuando se identificarán con los adolescentes de su grupo que consuman drogas. Finalmente, dada la multifactorialidad del fenómeno, aun cuando se constate que hay múltiples influencias provenientes del ámbito familiar sobre la iniciación y el hábito de consumo, se propone un análisis comprehensivo de los factores determinantes, teniendo en cuenta el carácter multideterminado de semejante problemática.

\section{Método}

\section{Muestra}

Se ha elegido mediante un muestreo intencional de áreas cuatro Centros de Enseñanza Secundaria del Municipio de Mieres de la Comarca del Caudal (Principado de Asturias, España). Se ha empleado un muestreo sistemático por conglomerados para la selección de los cursos académicos, estando integrada la muestra por 750 alumnos, de los cuales 380 son chicas ( $51.00 \%$ de la muestra) y 370 son chicos (49.00\% restante), con un rango de edad que oscila entre un mínimo de 12 años y un máximo de 18, estando situada la moda en 15 años (Media=14.69). Ha de concretarse que la selección de este nivel de edad correspondiente a la adolescencia media se ha efectuado con objeto de investigar el efecto de modelado familiar y del grupo de iguales en edades en las que se produce la iniciación al consumo de sustancias psicoactivas tales como el alcohol y el tabaco, así como por la importancia que, por sí mismo, adquieren las agencias socializadoras. De acuerdo con algunas de las características sociodemográficas de la muestra pertinentes al objeto de estudio, tales como el estatus sociofamiliar, se indica que las categorías profesionales más representativas son las de obrero cualificado para el padre y de ama de casa para la madre $(61.1 \%$, n=347 y 75.9\%, n=444, respectivamente). Los indicadores de condición socioeconómica, tales como la categoría profesional, han de verse complementados por la información asociada al nivel cultural paterno y materno, más interesante a nivel psicosociológico. A partir de su análisis se concreta que los estudios primarios representan el nivel de estudios más frecuente tanto entre los padres $(61.0 \%, \mathrm{n}=345)$ como entre las madres $(65.8 \%, \mathrm{n}=426)$ de los alumnos que integran la muestra. La mayoría de los alumnos se perciben como integrantes de la clase media, si bien son conscientes de las condiciones desfavorecedoras del entorno que habitan en unas condiciones socioeconómicas de crisis en una zona en proceso de desindustrialización minera.

\section{Variables investigadas e Instrumentos de evaluación}

En este estudio han sido objeto de análisis los procesos interaccionales desplegados en los vínculos paterno-filiales con referencias explícitas a los procesos de socialización y modelado. En concreto, se evalúan los estilos educativos paterno/materno y la percepción valorativa de tales vínculos por parte de sus hijos adolescentes, el tipo de relación afectiva que les vincula y los enfrentamientos y tipos de apoyos brindados, así como experiencias paternas con las drogas, cuestiones todas ellas de gran relevancia psicosocial y cuya conexión con el consumo de sustancias psicoactivas, ya sea como factor de riesgo o protector, también ha sido explicitado en el abordaje teórico. En concreto, se han analizado cuestiones tales como la manifestación paternal de afecto, el grado de entendimiento autopercibido, la satisfacción con el estilo educativo paterno, la manifestación de señales inequívocas de aceptación, comprensión y apoyo, la constatación de la preocupación e interés por las actividades del adolescente o la potenciación del respeto de las opiniones y expresión de sentimientos de orgullo, entre otras. Junto a estas variables se emplean otras mediante las que se miden aspectos negativos de semejante relación tales como aquéllas en las que se incide sobre el posible empleo del castigo como medida sancionadora, las dificultades percibidas en la comunicación entre padres e hijos y el reconocimiento de un ambiente conflictuado o el análisis del establecimiento de un alto nivel de exigencia paterno junto al empleo del chantaje emocional, la infravaloración y deseo de ajuste a un modelo idealizado, el control de necesidades percibidas o el análisis de la percepción de un trato desigual con respecto al resto de hermanos tanto negativo como un trato de favor. 
Respecto a los instrumentos de evaluación, se ha empleado una actualización del original instrumento EMBU (Perris, Jaconbon, Lindström, von Knorring \& Perris, 1980) Cuestionario de Educación Familiar, inventario sueco de 81 ítems formado por catorce subescalas que dan un índice del grado de disciplina familiar. En concreto, se ha utilizado la versión SOC-30 mediante la que se evalúa la percepción que tienen los hijos del proceso de socialización familiar, aplicada al análisis de la comunicación intrafamiliar (Herrero, 1992) y vinculadas al estudio del consumo de alcohol por parte de los hijos adolescentes y sus implicaciones (Pons, 1994; Pons \& Berjano, 1997). Se ha realizado un análisis factorial con rotación Varimax del instrumento SOC-30 obteniéndose cuatro dimensiones teóricas, las relativas a Apoyo, Castigo-Coerción, Sobreprotección/Control y Reprobación. Esta escala está formada a partir de una selección de ítems de la $E M B U$ y presenta una gran robustez y consistencia interna. En nuestro caso, se cumplen esas condiciones psicométricas, habiéndose hallado la misma estructura factorial original. Se ha obtenido un 42.9 por ciento de varianza explicada, correspondiendo del total acumulado un porcentaje elevado del 23 por ciento al factor $1 \mathrm{y}$ resultando bastante inferiores los del resto (8.7, 6.6 y 4.6, respectivamente). La dimensión que se ha calificado como Apoyo está integrada por once ítems e incluye variables que exploran el clima afectivo paterno-filial, concitando apoyos en momentos de crisis personales, con frecuentes manifestaciones recíprocas de cariño y apoyo incondicional, así como muestras de respeto, satisfacción y orgullo que actúan como reforzadores. Prácticas disciplinares en las que se recurre a la agresión física y donde se emplea violencia psicológica en forma de chantaje emocional y exacerbación del sentimiento del culpa como mecanismo de acción básico correctivo dan contenido a la dimensión 2 CastigoCoerción. Cinco ítems integran la tercera dimensión que evalúan la situación percibida de los hijos sometidos a la imposición de normas mediante las que se ejerce control parental, dimensión que ha sido denominada Sobreprotección/Control. Por último, la cuarta dimensión teórica subyacente es la correspondiente al factor Reprobación en la que se valora el grado en que los hijos perciben y asimilan la desaprobación paterna, así como las consecuencias de tales prácticas basadas en el ejercicio del chantaje emocional que cursan con sentimientos de culpabilidad en los adolescentes.

A partir del análisis de la consistencia interna de la escala SOC-30 se constata que existe una adecuada estructuración y fiabilidad superando el valor del coeficiente Alpha de Cronbach .85 para el total de los treinta ítems que integran la escala y para una muestra válida de 588 adolescentes. Al proceder a analizarlo para cada una de las dimensiones teóricas ha de concluirse que los mejores resultados (con valores que oscilan entre .8637 y .7285) se han obtenido para las dimensiones Apoyo y Castigo-Coerción, mientras que para las dos restantes los valores del indicador, así como de las correspondientes correlaciones múltiples, son moderados.

Se han evaluado actitudes ante el consumo de alcohol y otras drogas mediante el instrumento Autoinforme de Consumo de Sustancias Psicoactivas (Santacreu \& Froján, 1994) que consta de treinta ítems medidos en una escala Likert con cinco niveles en los que se analizan actitudes hacia las drogas, su consumo y usuarios de acuerdo con una triple dimensionalidad: cognitivas (creencias y expectativas), emocionales (sentimientos y valoraciones) y comportamentales (disposición para actuar). Su estructura factorial se define por siete factores: el factor 1 (AICA-FACTOR1) etiquetado como Concienciación ante los efectos negativos y Actitud contraria al consumo de drogas que incluye aseveraciones concernientes al reconocimiento de los efectos dañinos que provoca el consumo de drogas, disposiciones conductuales y sociocognitivas de rechazo de su uso; el factor 2 (AICA-FACTOR2) Actitud de Resistencia al consumo de drogas mediante el que se reafirma la defensa de actitudes contrarias a las drogas; la denominación de Rechazo de invitación de Tabaco y Drogas Ilegales y de Rechazo de invitación de Alcohol se adjudica, respectivamente a los factores 3 (AICA-FACTOR3) y 4 (AICA-FACTOR4) que exploran cuestiones relativas a la resistencia frente a la incitación al consumo, valoración de la conducta de abstinencia en un grupo de amigos consumidores y la ausencia de curiosidad para probar drogas institucionalizadas (alcohol y tabaco); en el factor 5 (AICA-FACTOR5) etiquetado como Concienciación ante los efectos negativos y Actitud contraria al consumo de drogas institucionalizadas se incide en la misma cuestión que en el primero de los constructos definidos, si bien en esta oportunidad referido específicamente al consumo de tabaco y de alcohol; bajo la etiqueta Drogas e identidad de ser mayor se ha definido el factor 
6 (AICA-FACTOR6) y, finalmente, el factor 7 (AICA-FACTOR7), denominado Admiración ante no-usuarios de drogas institucionalizadas, consta de dos ítems en los que se apela al componente motivacional de la actitud, incidiéndose en la valoración positiva de quienes no son consumidores de tabaco y alcohol.

También se ha empleado el Cuestionario de Actitudes hacia el consumo de sustancias psicoactivas (Maciá, Olivares \& Méndez, 1993, adaptado de Maciá, 1986) integrado por veinte ítems en los que se incide sobre el análisis de las dimensiones valorativa y reactiva de las actitudes, fundamentalmente, tanto ante el alcohol como hacia drogas ilegales. Se ha definido el factor 1 (ACTITUD. FACTOR1) atendiendo al contenido temático de los ítems que más saturan en tal constructo, de modo que bajo el etiquetaje Disposición para experimentar y habituarse a las drogas se han incluido cinco variables mediante las que se evidencia la tendencia a convertirse en un experimentador de todo tipo de drogas e incluso a convertirse en un consumidor habitual de las mismas. Actitud permisiva ante el consumo que se amplía en el factor 2 (ACTITUD.FACTOR2) (Disposición para experimentar y habituarse al alcohol) a la experimentación y posterior habituación al consumo de alcohol. Frente a ambos, los factores 3 (ACTITUD.FACTOR3) y 4 (ACTITUD.FACTOR4) se definen por la manifestación de una actitud contraria al consumo y que bajo el calificativo de Actitud de Resistencia frente al consumo de alcohol y Actitud de Resistencia frente al consumo de drogas, respectivamente, hemos etiquetado al determinarse la revelación de una tendencia al rechazo de las conductas de riesgo y una potenciación de las estrategias preventivas y de defensa pública de la misma en oportunidades de incitación. Finalmente, bajo la denominación Abandono de ambientes y compañías incitadores se alude factor 5 (ACTITUD.FACTOR5) en el que se ratifica, al igual que en las dos precedentes, la intención de reafirmar su actitud de resistencia y de prevenir situaciones de riesgo en las que se maximiza tal contingencia y que pueden ser inductoras de posibles experimentaciones no deseadas.

\section{Procedimiento}

Miembros del equipo investigador administraron anónimamente las escalas al colectivo de adolescentes especificado, una vez desarrollado el correspondiente acuerdo con los Departamentos de Orientación de los citados Centros de Educación Secundaria. La investigación comprehensiva de la problemática del consumo juvenil de sustancias psicoactivas ha sido de carácter longitudinal a lo largo de dos cursos académicos, de modo que las labores de recogida de datos se han complementado con el diseño e implementación de un programa educativo-preventivo (informativo, de entrenamiento en habilidades sociales e intervención con los padres) y de carácter sociocomunitario bajo la denominación “Campaña Previene” evaluado satisfactoriamente por agencias implicadas en su implementación (a nivel institucional, de asociaciones, padres, docentes, etc.). En esta oportunidad, exclusivamente se exponen algunos de los resultados descriptivos concernientes a las principales variables del ámbito familiar y del grupo de iguales ya explicitadas que corresponden a las labores de primera encuestación.

\section{Resultados}

De acuerdo con los resultados hallados se ha confirmado que los adolescentes valoran positivamente su relación con los padres, considerándolos como referentes durante una etapa de cuestionamientos psicosociales y crisis identitarias varias (Moral \& Ovejero, 1998a, 1998b, 2004). Se ha obtenido un amplio consenso ante afirmaciones en las que se evalúa el grado de comprensión e identificación, el nivel de expectativas inducido, el apego emocional o las manifestaciones de afecto y complicidad, así como identificadores de problemas en la comunicación paterno-filial, empleo de medidas disciplinarias u otras coercitivas o desaprobaciones paternas con las identidades de los hijos, entre otras conductas analizadas.

Los principales resultados del estudio descriptivo se reseñan a continuación:

a) A partir del análisis del factor Apoyo se reafirma la importancia concedida a este indicador con 
elevados porcentajes de respuesta afirmativa adscrito a un solo nivel denotaivos de manifestación incondicional de amor y apoyo. Por ejemplo se ha obtenido un porcentaje de $54.7 \%$ en el nivel siempre ante la afirmación "Siento que mis padres me quieren" (SOC02) o de un 52.3\% en la medida de la percepción de la intensidad del vínculo (SOC17 “Tengo la sensación de que mis padres quieren estar a mi lado”), así como ante la percepción de frecuentes manifestaciones recíprocas de cariño (véase SOC28, “Tengo la sensación de que hay ternura y cariño entre mis padres y yo", 53.7\%) y búsquedas de ayuda y comprensión (véase SOC20 "Cuando me encuentro triste busco ayuda y comprensión en mis padres”, 48.9\%), a lo que se suman muestras de respeto, satisfacción y orgullo que actúan como reforzadores;

b) Semejante tendencia de respuesta se ve corroborada mediante la referencia a actitudes paternas diametralmente opuestas a las anteriores como son aquéllas en las que se incide sobre el empleo del Castigo y la Coerción como prácticas disciplinares ejemplarizantes en las que se recurre a la agresión física y donde se emplea el chantaje emocional y la exacerbación del sentimiento de culpa. Así el porcentaje de respuesta más elevado hallado en un nivel de respuesta corresponde al obtenido ante la afirmación "Mis padres me pegan sin motivo" (SOC25) con un rechazo (nivel nunca) del 85.7\%, seguido del empleo de castigos de privación (SOC29, "Mis padres me han mandado a la cama sin cenar", 79.1\%) u otras medidas como inflingir castigos corporales con un $74.9 \%$ de rechazo ante la afirmación "Mis padres me imponen más castigos corporales de los que merezco" (SOC09);

c) De la evaluación de la percepción valorativa del empleo de la Sobreprotección y el Control por parte de los padres se extrae la confirmación de la responsabilidad e implicación paterna en labores de supervisión del rendimiento académico de sus hijos adolescentes con un $80.7 \%$ de acuerdo en el nivel de respuesta siempre ante la afirmación "Mis padres muestran interés en que obtenga buenas notas" (SOC11) y ante indicadores de sobreprotección y control, de acuerdo a la percepción de los adolescentes, los padres dan muestras de un excesivo celo comparativamente con los de otros compañeros, ello se constata ante afirmaciones como "Puedo ir donde quiera sin que mis padres se preocupen demasiado" (SOC27), ante la que un 88.2\% (consideración conjunta de los niveles 3=Algunas Veces, $4=$ Pocas veces y $5=$ Nunca) rechazan abiertamente esta posibilidad u otras en las que los porcentajes de respuesta se adscriben a niveles intermedios (véase SOC06 y SOC22); y, finalmente,

d) Se comprueba que al analizar el grado en que los hijos perciben y asimilan la desaprobación paterna, así como las consecuencias de tales prácticas, y la inducción a que los adolescentes sean diferentes en diversos aspectos se constata que los padres recurren al empleo del chantaje emocional medido bajo la inducción del sentimiento de tristeza paterna ante la realización de una falta (SOC18 "Mis padres utilizan expresiones como: "Si haces eso, voy a ponerme muy triste"), si bien más del setenta por ciento de los adolescentes (71.1\%) indican que sus padres no emplean semejantes tácticas persuasivas, así como muestras de auto-inculpación del desasosiego paterno (SOC14 "Tengo la sensación de que cuando mis padres están tristes yo soy la causa de su estado", con un 48.6\% de rechazo) y proyección del sentimiento de culpa (SOC10 "Cuando a mis padres les parece mal lo que hago se entristecen hasta el punto de que me siento culpable de lo que he hecho", 23.9\%), todo lo cual se completa con el recurso al empleo del ejercicio de influencia paterna con objeto de modificar al adolescente en algún aspecto en aras de promover que sea diferente y mejor (véase SOC04 "Mis padres tratan de influirme para que sea una persona importante" con porcentajes de acuerdo del 55.2\% niveles conjuntos siempre y casi siempre). En su conjunto, se confirma un patrón interaccional bien establecido con el recurso de la comprensión y el cariño, la elicitación del afecto paterno, y la puesta en práctica de un adecuado estilo disciplinar, de acuerdo con las percepciones valorativas de sus hijos adolescentes. 
Tabla 1. - Percepción de los procesos de Socialización familiar (Apoyo, Castigo-Coerción, Sobreprotección/Control y Reprobación).

\begin{tabular}{|c|c|c|c|c|c|}
\hline SOCIALIZACIÓN FAMILIAR & Siempre & $\begin{array}{l}\text { muchas } \\
\text { veces }\end{array}$ & $\begin{array}{l}\text { algunas } \\
\text { veces }\end{array}$ & $\begin{array}{l}\text { pocas } \\
\text { veces }\end{array}$ & nunca \\
\hline $\begin{array}{l}\text { SOC01 ¿Te han demostrado con pala- } \\
\text { bras y gestos que te quieren? }\end{array}$ & 50.0 & 30.4 & 12.2 & 4.3 & 3.1 \\
\hline $\begin{array}{l}\text { SOC02 ¿Te sientes querido por tus pa- } \\
\text { dres? }\end{array}$ & 54.7 & 13.0 & 10.7 & 4.6 & 3.2 \\
\hline $\begin{array}{l}\text { SOC03 ¿Ocurre que tus padres te cas- } \\
\text { tigan incluso por cometer pequeñas } \\
\text { faltas? }\end{array}$ & 4.9 & 6.8 & 11.7 & 24.6 & 52.0 \\
\hline $\begin{array}{l}\text { SOC04 ¿Tratan tus padres de influirte } \\
\text { para que seas una persona importante? }\end{array}$ & 22.9 & 22.2 & 22.8 & 13.2 & 18.8 \\
\hline $\begin{array}{l}\text { SOC05 ¿Crees que tu padre o tu madre } \\
\text { desean que tú seas diferente en algún } \\
\text { aspecto? }\end{array}$ & 8.5 & 9.0 & 22.2 & 21.1 & 39.2 \\
\hline $\begin{array}{l}\text { SOC06 ¿Ocurre que tus padres te pro- } \\
\text { híben hacer cosas que otros niños de tu } \\
\text { edad pueden hacer por miedo a que te } \\
\text { suceda algo? }\end{array}$ & 13.4 & 21.1 & 24.3 & 22.9 & 18.3 \\
\hline $\begin{array}{l}\text { SOC07 ¿Se preocupan tus padres de } \\
\text { saber qué haces cuando no estás en } \\
\text { casa? }\end{array}$ & 53.0 & 20.5 & 15.6 & 7.3 & 3.6 \\
\hline $\begin{array}{l}\text { SOC08 Si te van las cosas mal, ¿tienes } \\
\text { la sensación de que tus padres tratan de } \\
\text { comprenderte y animarte? }\end{array}$ & 44.1 & 24.1 & 17.0 & 9.3 & 5.4 \\
\hline $\begin{array}{l}\text { SOC09 ¿Te imponen más castigos cor- } \\
\text { porales de los que mereces? }\end{array}$ & 2.4 & 2.5 & 8.0 & 12.2 & 74.9 \\
\hline $\begin{array}{l}\text { SOC10 Si a tus padres les parece mal } \\
\text { lo que haces, ¿se entristecen hasta tal } \\
\text { punto que te sientes culpable por lo que } \\
\text { has hecho? }\end{array}$ & 8.8 & 13.8 & 28.7 & 24.8 & 23.9 \\
\hline $\begin{array}{l}\text { SOC11 ¿Muestran tus padres interés en } \\
\text { que saques buenas notas? }\end{array}$ & 80.7 & 10.9 & 3.6 & 2.9 & 2.0 \\
\hline $\begin{array}{l}\text { SOC12 ¿Sientes que tus padres te ayu- } \\
\text { dan cuando te enfrentas a una tarea di- } \\
\text { fícil? }\end{array}$ & 50.5 & 21.7 & 17.5 & 5.6 & 4.8 \\
\hline $\begin{array}{l}\text { SOC13 Ocurre que tus padres te digan: } \\
\text { "Tú que res tan mayor o tú que res un } \\
\text { chico o una chica no debes comportan- } \\
\text { te de esa manera? }\end{array}$ & 10.4 & 14.1 & 23.9 & 25.6 & 26.0 \\
\hline $\begin{array}{l}\text { SOC14 Cuando tus padres están tris- } \\
\text { tes ¿tienes la impresión de que ellos } \\
\text { piensan que ti eres el causante de su } \\
\text { estado? }\end{array}$ & 6.1 & 5.9 & 14.8 & 24.8 & 48.6 \\
\hline $\begin{array}{l}\text { SOC15 ¿Te demuestran tus padres que } \\
\text { están satisfechos contigo? }\end{array}$ & 35.7 & 30.6 & 20.7 & 8.1 & 4.9 \\
\hline $\begin{array}{l}\text { SOC16 ¿Crees que tus padres respetan } \\
\text { tus opiniones? }\end{array}$ & 38.4 & 27.8 & 20.4 & 8.7 & 4.8 \\
\hline $\begin{array}{l}\text { SOC17 ¿Tienes la sensación de que tus } \\
\text { padres quieren estar a tu lado? }\end{array}$ & 52.3 & 24.8 & 14.6 & 5.9 & 2.4 \\
\hline
\end{tabular}




\begin{tabular}{|l|c|c|c|c|c|}
\hline $\begin{array}{l}\text { SOC18 ¿Utilizan tus padres expresio- } \\
\text { nes como: 'Si haces eso, voy a poner- } \\
\text { me muy triste’? }\end{array}$ & 2.2 & 2.7 & 5.4 & 18.5 & 71.1 \\
\hline $\begin{array}{l}\text { SOC19 ¿Tus padres alaban frecuente- } \\
\text { mente tu comportamiento? }\end{array}$ & 13.1 & 20.0 & 33.8 & 24.1 & 9.0 \\
\hline $\begin{array}{l}\text { SOC20 Si te encuentras triste, ¿puedes } \\
\text { buscar ayuda y comprensión en tus pa- } \\
\text { dres? }\end{array}$ & 48.9 & 16.0 & 18.3 & 8.5 & 8.3 \\
\hline $\begin{array}{l}\text { SOC21 ¿Te castigan tus padres sin que } \\
\text { tú hayas hecho nada malo? }\end{array}$ & 4.4 & 4.2 & 8.7 & 14.3 & 68.4 \\
\hline $\begin{array}{l}\text { SOC22 ¿Te dejan tus padres hacer las } \\
\text { mismas cosas que pueden hacer tus } \\
\text { amigos? }\end{array}$ & 16.8 & 24.3 & 34.8 & 15.8 & 8.3 \\
\hline $\begin{array}{l}\text { SOC23 ¿Te dicen tus padres que no } \\
\text { están de acuerdo con la forma de com- } \\
\text { portarte en casa? }\end{array}$ & 7.0 & 9.7 & 23.1 & 29.0 & 31.2 \\
\hline $\begin{array}{l}\text { SOC24 ¿Te castigan tus padres con du- } \\
\text { reza, incluso por cosas que no tienen } \\
\text { importancia? }\end{array}$ & 3.7 & 4.2 & 8.1 & 19.5 & 64.3 \\
\hline $\begin{array}{l}\text { SOC25 ¿Te pegan tus padres sin mo- } \\
\text { tivo? }\end{array}$ & 2.2 & 1.4 & 4.2 & 6.5 & 85.7 \\
\hline SOC26 ¿Te pegan tus padres? & 1.4 & 2.0 & 7.0 & 18.3 & 71.3 \\
\hline $\begin{array}{l}\text { SOC27 ¿Puedes ir donde quieres sin } \\
\text { que tus padres se preocupen demasiado } \\
\text { por ello? }\end{array}$ & 3.9 & 9.5 & 24.3 & 31.2 & 31.1 \\
\hline $\begin{array}{l}\text { SOC28 Tienes la sensación de que hay } \\
\text { cariño y ternura entre tú y tus padres? }\end{array}$ & 53.7 & 23.1 & 22.6 & 7.1 & 3.6 \\
\hline $\begin{array}{l}\text { SOC29 ¿Te han mandado tus padres a } \\
\text { la cama sin cenar? }\end{array}$ & 1.4 & 2.5 & 6.6 & 10.4 & 79.1 \\
\hline $\begin{array}{l}\text { SOC30 ¿Te manifiestan tus padres que } \\
\text { están satisfechos contigo mediante ex- } \\
\text { presiones físicas cariñosas, como darte } \\
\text { palmadas en la espalda? }\end{array}$ & 27.9 & 25.6 & 26.7 & 9.7 & 10.2 \\
\hline
\end{tabular}

Las características psicosociales que definen la esfera socioafectiva del adolescente están directamente relacionadas con los apoyos familiares percibidos que se someten a diversos cambios durante la adolescencia, debilitándose las relaciones paterno-filiales a ciertas edades y adoptando otra significación y modo de manifestación a partir de la adolescencia media y tardía. En este sentido, sería esperable que las relaciones con los padres fuesen más valoradas en los primeros años de la adolescencia (12-13 años) que con posterioridad, atravesándose por una fase crítica durante la adolescencia media (15 y 16 años). Tal y como se constata al analizar los resultados obtenidos, se confirma la existencia de diferencias en la percepción y valoración del trato con los padres en función del nivel de edad. Se han adscrito ciertas edades a unos determinados niveles (nivel 1: 12-14 años, nivel 2: 14 años, nivel 3: 15 años y nivel 4: 16 o más años) con la intención de indagar tanto en el comienzo de la adolescencia, como en los llamados años intermedios sobre la posible existencia de cambios cualitativos y/o cuantitativos. Se ha efectuado un análisis del grado de acuerdo o desacuerdo con el tipo de socialización familiar, el estilo educativo percibido, la identificación o enfrentamiento con los padres, la valoración del trato o la manifestación de quejas asociadas a la falta de afecto, el empleo del chantaje emocional o el trato diferencial con respecto a otros hermanos, entre otros muchos factores, aspectos estudiados en el instrumento en el SOC-30 y cuyos resultados, se exponen en la Tabla 2. Se ha comprobado que, de acuerdo con el nivel de edad contemplado, se han hallado diferencias significativas en los factores de Apoyo (socfactor1) (donde se han invertido los 
valores) y Castigo-Coerción (socfactor2) no resultando significativas las diferencias halladas en los factores Sobreprotección/Control y Reprobación. Los adolescentes de mayor edad perciben menor apoyo paternal y mayor empleo de métodos coercitivos que interpretan como indicios de una férrea disciplina familiar a la que creen verse sometidos. Se comprueba que tales diferencias en el caso del factor etiquetado como Compresión y Apoyo se manifiestan entre el primer nivel de edad (12-13 años) y los superiores mostrando puntuaciones medias más elevadas indicadoras de una percepción más positiva de la relación afectiva y muestras de cariño brindada por los padres. En cambio, en los factores relativos a Castigo-Coerción los valores más elevados (una vez invertido el sentido de los ítems) corresponden al reconocimiento de menores sentimientos de este estilo que se concentran, como en la oportunidad anterior, en el nivel de edad más bajo, si bien esta tendencia ha de ser interpretada en el sentido de que los adolescentes de estas edades reportan menores quejas asociadas al empleo de este estilo educativo impositivo y corrector. Ello se comprueba, en líneas generales, al desglosar en cuatro los niveles de edad establecidos (véase Gráfico1).

Tabla 2. Diferencias y contrastes post hoc en los factores de socialización familiar según el nivel de edad (ANOVA).

\begin{tabular}{|c|c|c|c|c|c|c|}
\hline \multirow{3}{*}{$\begin{array}{l}\text { RELACIÓN PADRES / } \\
\text { NIVEL DE EDAD }\end{array}$} & \multirow{3}{*}{$\mathrm{F}$} & \multirow{3}{*}{$\mathrm{p}$} & \multicolumn{4}{|c|}{ NIVEL DE EDAD } \\
\hline & & & \multicolumn{4}{|c|}{$12-13 \quad 14-16>16$} \\
\hline & & & \multicolumn{4}{|c|}{ Medias y Contrastes post-hoc } \\
\hline \multirow[t]{2}{*}{ Aроуо } & 7.7928 & .0005 & 20.462 & $22 \quad 23.46$ & $45 \quad 24$. & 7164 \\
\hline & & & \multicolumn{4}{|c|}{$[$ NIVEL $c$ y $b>a]$} \\
\hline Castigo-Coerción & 2.5134 & .0819 & 26.6050 & 26.44 & \multicolumn{2}{|c|}{27.5970} \\
\hline Sobreprotección & .9557 & .3851 & 12.6303 & 12.92 & \multicolumn{2}{|c|}{12.7015} \\
\hline Reprobación & 1.8232 & .1624 & 26.3529 & 25.52 & \multicolumn{2}{|c|}{25.1045} \\
\hline \multirow{3}{*}{$\begin{array}{l}\text { RELACIÓN PADRES / } \\
\text { NIVEL DE EDAD }\end{array}$} & \multirow{3}{*}{ F. } & \multirow{3}{*}{$p$} & \multicolumn{4}{|c|}{ NIVEL DE EDAD } \\
\hline & & & \multirow{2}{*}{\multicolumn{4}{|c|}{$\begin{array}{llll}12-13 & 14 & 15 & 16 \\
& \text { o }> \\
\text { Medias y Contrastes } & \text { post-hoc }\end{array}$}} \\
\hline & & & & & & \\
\hline \multirow[t]{2}{*}{ Aроуо } & 6.8941 & .0001 & 20.4622 & 22.2794 & 24.6301 & 23.7500 \\
\hline & & & \multicolumn{4}{|c|}{$[$ NIVEL $c$ y $d>a]$} \\
\hline \multirow[t]{2}{*}{ Castigo-Coerción } & 4.4620 & .0041 & 26.6050 & 26.9338 & 25.7759 & 27.2697 \\
\hline & & & \multicolumn{4}{|c|}{$[$ NIVEL $d$ y $b>c] /[$ NIVEL $d>c]$} \\
\hline Sobreprotección & 2.0082 & .1117 & 12.6303 & 12.5588 & 13.1034 & 12.9605 \\
\hline Reprobación & 1.5483 & .2010 & 26.3529 & 25.4853 & 25.1609 & 25.8026 \\
\hline
\end{tabular}


Gráfico 1. Representación gráfica de los factores de socialización familiar en función del nivel de edad.

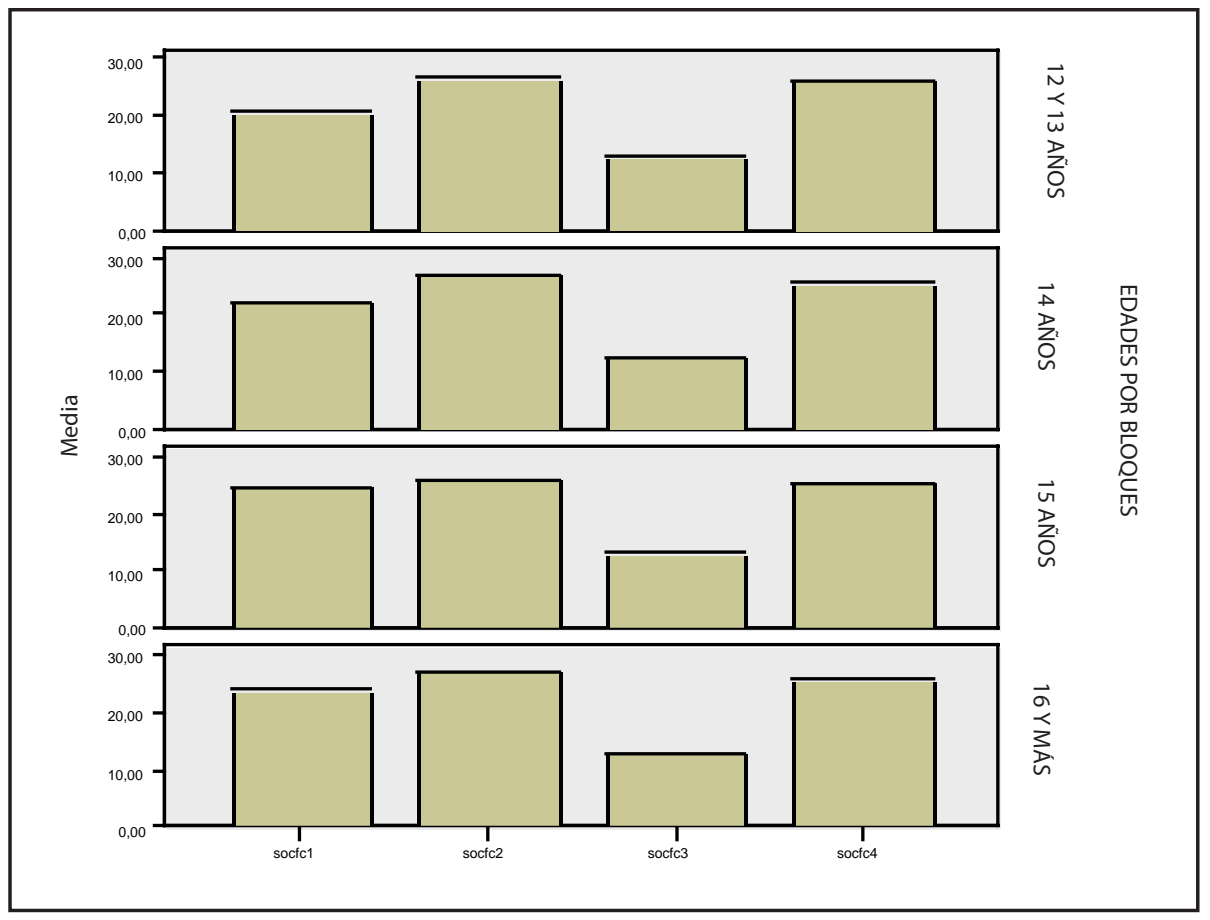

Determinar la influencia ejercida por el efecto de modelado de los padres sobre las actitudes hacia el consumo de sustancias psicoactivas de los adolescentes ha representado un objeto de estudio prioritario. En este sentido, se ha procedido a analizar las diferencias actitudinales manifiestas en función del nivel de apoyo y conflictividad familiar percibido, así como la influencia ejercida bajo efectos de modelado por las experiencias de consumo por las experiencias de consumo de ambas agencias socializadoras. De acuerdo con esta última cuestión, se han relacionado tales experimentaciones con las actitudes hacia el consumo de sustancias psicoactivas confirmándose para la mayoría de los casos objeto de análisis la existencia de diferencias significativas en las puntuaciones medias en función de las experiencias paternas de consumo de sustancias como tabaco, alcohol, cannabis, somníferos, heroína y cocaína.

En concreto, se constata la significación de tales diferencias para cada una de las drogas con las siguientes matizaciones y salvedades: $a$ ) al contrastar los efectos sobre las actitudes que se asocian al efecto de modelado de los padres consumidores de drogas institucionalizadas como el tabaco o el alcohol y de otras como los derivados canábicos que se hace extensivo a aquéllos que consumen somníferos o han experimentado con heroína y/o cocaína se confirma que las actitudes de sus hijos adolescentes son más permisivas en el indicador Actitud global hacia el consumo de alcohol (AICATOTAL), así como en la Actitud de Resistencia al consumo de drogas (AICA.FACTOR2), ante el Rechazo de invitación de Tabaco y Drogas Ilegales (AICA.FACTOR3), así como específicamente de Alcohol (AICA.FACTOR4), y manifiestan menor Concienciación ante los efectos negativos y Actitud ante el consumo de drogas institucionalizadas (AICA.FACTOR5) (salvedad en este caso de los padres que consumen tabaco donde las diferencias no han resultado significativas, $\mathrm{F}=.7782$, $\mathrm{p}=.3780$ ). En todos estos factores analizados las diferencias halladas son significativas para cada uno de los casos expuestos, y a ello se suma la constatación de diferencias en el sentido predicho -esto es, efecto de modelado paterno sobre las actitudes e inclinaciones para el consumo de los adolescentes induciendo una mayor permisividad en su conjunto-, en otros factores, tales como la 
vinculación Drogas e identidad de ser mayor (AICA.FACTOR6) en esta oportunidad abundando en la creencia de que la experimentación con sustancias psicoactivas les hace sentirse mayores lo cual se confirma para los casos de los padres que experimentan con alcohol, cannabis, somníferos y heroína no alcanzando la significación para quienes informan de consumir tabaco $(\mathrm{F}=.9117, \mathrm{p}=.3400)$ y experimentar con cocaína ( $\mathrm{F}=2.1481$, p=.1432). Finalmente, en el indicador de Admiración ante no-usuarios de drogas institucionalizadas (AICA.FACTOR7) las diferencias se concentran en los casos de padres consumidores de alcohol ( $\mathrm{F}=8.9647, \mathrm{p}=.0028)$ y de derivados canábicos ( $\mathrm{F}=6.0543, \mathrm{p}=.0141)$, de modo que se incurre en un sesgo de mentalidad del usuario mediante el cual se induce una percepción valorativa menor de quienes no experimentan con drogas institucionalizadas entre aquellos adolescentes cuyos padres son usuarios de tales sustancias psicoactivas; $b$ ) por lo que respecta al análisis de los efectos predichos sobre la dimensión comportamental (inclinación para el consumo) de la esfera actitudinal el mayor efecto de modelado derivado de las experiencias paternas con las drogas se concentra en los familiares usuarios de alcohol, de derivados canábicos y de somníferos, de modo que en todos los indicadores analizados se ha confirmado la significación de las diferencias indicativas de una disposición en los hijos adolescentes más proclive a experimentar y habituarse a las drogas ilegales (ACTITUD.FACTOR1), así como a experimentar y habituarse al alcohol (ACTITUD.FACTO R2), unas actitudes que denotan menor resistencia frente al consumo de alcohol (ACTITUD.FACTOR3) y frente al consumo de otras drogas (ACTITUD.FACTOR4), así como una menor tendencia al abandono de ambientes y compañías incitadores (ACTITUD. FACTOR5) vinculada a la evitación de factores de riesgo moduladores de los usos (véase Tabla 3).

En su conjunto, se ha confirmado la existencia de diferencias significativas en las actitudes hacia el consumo de sustancias psicoactivas en hijos adolescentes en los indicadores explicitados, en función de las experiencias paternas con las drogas.

Tabla 3. Modelado paterno sobre las actitudes hacia el consumo de drogas.

\begin{tabular}{|c|c|c|c|c|c|c|c|c|c|}
\hline \multirow{2}{*}{$\begin{array}{l}\text { ACTITUD HACIA } \\
\text { EL CONSUMO / } \\
\text { MODELADO FAMI- } \\
\text { LIAR }\end{array}$} & \multicolumn{3}{|c|}{$\begin{array}{l}\text { CONSUMO PATERNO } \\
\text { DE TABACO }\end{array}$} & \multicolumn{3}{|c|}{$\begin{array}{l}\text { CONSUMO PATERNO } \\
\text { DE ALCOHOL }\end{array}$} & \multicolumn{3}{|c|}{$\begin{array}{l}\text { CONSUMO PATER- } \\
\text { NO DE CANNABIS }\end{array}$} \\
\hline & $\mathrm{F}$ & SÍ & NO & $\mathrm{F}$ & SÍ & NO & $\mathrm{F}$ & SÍ & $\mathrm{NO}$ \\
\hline Actitudes Globales & $5.2636^{* *}$ & 2.14 & 2.32 & $36.238 *$ & 2.05 & 2.40 & $40.499 *$ & 2.24 & 2.81 \\
\hline AICA.FACTOR1 & $1.8090 * *$ & 12.44 & 413.28 & $21.153^{*}$ & 11.70 & 13.80 & $29.341 *$ & 12.80 & 16.62 \\
\hline AICA.FACTOR2 & $5.2794^{* *}$ & 13.50 & 14.92 & $21.163^{*}$ & 13.28 & 15.36 & $32.470^{*}$ & 14.35 & 18.31 \\
\hline AICA.FACTOR3 & $3.8032 * * *$ & * 8.62 & 9.72 & $11.311^{*}$ & 8.602 & 9.99 & $26.929 *$ & 9.25 & 12.56 \\
\hline AICA.FACTOR4 & $6.6885^{*}$ & 9.96 & 11.27 & $37.186^{*}$ & 9.54 & 11.77 & $32.709 *$ & 10.78 & 14.04 \\
\hline AICA.FACTOR5 & .7782 & 12.52 & 12.98 & $22.951 *$ & 11.67 & 13.46 & $8.032 *$ & 12.75 & 14.42 \\
\hline AICA.FACTOR6 & .9117 & 3.07 & 3.27 & $8.4882 *$ & 2.93 & 3.38 & $9.248 *$ & 3.17 & 3.89 \\
\hline AICA.FACTOR7 & .695 & 4.63 & 4.84 & $8.964 *$ & 4.42 & 4.99 & $6.054 * *$ & 4.74 & 5.47 \\
\hline ACTITUD.FACTOR1 & 2.517 & 19.74 & 19.16 & 8.9231* & 19.80 & 18.99 & $14.627 *$ & 19.39 & 17.78 \\
\hline ACTITUD.FACTOR2 & .7080 & 15.43 & 15.07 & $15.256^{*}$ & 15.96 & 14.75 & $14.451 *$ & 15.30 & 13.46 \\
\hline ACTITUD.FACTOR3 & $7.0342 *$ & 10.83 & 12.05 & $11.788^{*}$ & 11.07 & 12.24 & $10.786^{*}$ & 11.72 & 13.46 \\
\hline ACTITUD.FACTOR4 & 1.3716 & 6.47 & 6.90 & $8.0801 *$ & 6.31 & 7.08 & $8.448^{*}$ & 6.72 & 7.95 \\
\hline ACTITUD.FACTOR5 & $5.5804^{* *}$ & 8.53 & 9.35 & $27.235^{*}$ & 8.32 & 9.64 & $14.963 *$ & 9.09 & 10.62 \\
\hline
\end{tabular}




\begin{tabular}{|c|c|c|c|c|c|c|c|c|c|}
\hline \multirow{2}{*}{$\begin{array}{l}\text { ACTITUD HACIA EL } \\
\text { CONSUMO / MODE- } \\
\text { LADO FAMILIAR }\end{array}$} & \multicolumn{3}{|c|}{$\begin{array}{l}\text { CONSUMO PATERNO DE } \\
\text { SOMNÍFEROS }\end{array}$} & \multicolumn{3}{|c|}{$\begin{array}{l}\text { CONSUMO PATERNO } \\
\text { DE HEROÍNA }\end{array}$} & \multicolumn{3}{|c|}{$\begin{array}{l}\text { CONSUMO PATERNO } \\
\text { DE COCAÍNA }\end{array}$} \\
\hline & $\mathrm{F}$ & SÍ & NO & $\mathrm{F}$ & Sí & NO & F & SÍ & NO \\
\hline Actitudes Globales & $19.897 *$ & 2.28 & 3.12 & $11.422 *$ & 2.28 & 2.90 & $7.182 *$ & 2.28 & 2.75 \\
\hline AICA.FACTOR1 & $14.257 *$ & 13.05 & 18.60 & $4.447^{*}$ & 13.10 & 16.12 & $2.035^{* *}$ & 13.12 & 15.05 \\
\hline AICA.FACTOR2 & $24.082 *$ & 14.58 & 21.66 & $9.265^{*}$ & 14.63 & 18.93 & $4.139^{* *}$ & 14.66 & 17.38 \\
\hline AICA.FACTOR3 & $4.899 * *$ & 9.51 & 12.46 & $8.495 *$ & 9.49 & 13.25 & $9.163^{*}$ & 9.48 & 13.16 \\
\hline AICA.FACTOR4 & $14.515^{*}$ & 11.00 & 15.53 & $11.570^{*}$ & 11.61 & 14.93 & 8.919* & 11.01 & 14.27 \\
\hline AICA.FACTOR5 & $7.687^{*}$ & 12.84 & 16.20 & $3.692 * *$ & 12.86 & 15.12 & $3.320^{* * *}$ & 12.86 & 614.88 \\
\hline AICA.FACTOR6 & $3.400^{* * *}$ & 3.22 & 4.13 & $4.093^{* *}$ & 3.22 & 4.18 & 2.148 & 3.22 & 3.88 \\
\hline AICA.FACTOR7 & 1.995 & 4.80 & 5.66 & 1.639 & 4.80 & 5.56 & .403 & 4.81 & 5.16 \\
\hline ACTITUD.FACTOR1 & $19.113^{*}$ & 19.31 & 15.53 & $4.092 * *$ & 19.27 & 17.56 & .5351 & 19.25 & 18.66 \\
\hline ACTITUD.FACTOR2 & $9.774 *$ & 15.18 & 12.06 & 2.693 & 15.15 & 13.56 & 1.1382 & 15.14 & 14.16 \\
\hline ACTITUD.FACTOR3 & $3.154 * * *$ & 11.85 & $5 \quad 13.80$ & .0105 & 11.89 & 12.00 & .0037 & 11.89 & 11.83 \\
\hline ACTITUD.FACTOR4 & $4.536^{* *}$ & 6.80 & 8.66 & .0010 & 6.84 & 4.87 & .2681 & 6.85 & 6.44 \\
\hline ACTITUD.FACTOR5 & $9.707^{*}$ & 9.19 & 11.73 & $2.117 * * *$ & 10.3 & $37 \quad 9.21$ & 1.0653 & 9.22 & 10.00 \\
\hline
\end{tabular}

AICATOTAL Actitud global hacia el consumo de alcohol, AICA.FACTOR1 Concienciación ante los efectos negativos y Actitud contraria al consumo de drogas, AICA.FACTOR2 Actitud de Resistencia al consumo de drogas, AICA.FACTOR3 Rechazo de invitación de Tabaco y Drogas Ilegales, AICA.FACTOR4 Rechazo de invitación de Alcohol, AICA.FACTOR5 Concienciación ante los efectos negativos y Actitud contraria al consumo de drogas institucionalizadas, AICA.FACTOR6 Drogas e identidad de ser mayor, AICA.FACTOR7 Admiración ante no-usuarios de drogas institucionalizadas, ACTITUD.FACTOR1 Disposición para experimentar y habituarse a las drogas, ACTITUD.FACTOR2 Disposición para experimentar y habituarse al alcohol, ACTITUD.FACTOR3 Actitud de Resistencia frente al consumo de alcohol, ACTITUD.FACTOR4 Actitud de Resistencia frente al consumo de drogas, ACTITUD.FACTOR5 Abandono de ambientes y compañías incitadores.

Una vez que se han analizado las modulaciones a nivel actitudinal de las experiencias paternas con las drogas se ha comprobado la existencia de diferencias significativas en las percepciones valorativas de los modelos de socialización, estilos disciplinares, vínculos y apoyos descritos entre aquellos adolescentes que consumen o no una determinada sustancia psicoactivas, tanto legales como ilegales. En concreto, tal como se recoge en la Tabla 4, según las puntuaciones medias halladas, se confirma la importancia psicosocial del Apoyo (cálido clima afectivo paterno-filial, ofrecimiento de ayuda ante crisis personales, manifestaciones recíprocas de cariño y apoyo incondicional, muestras de respeto, satisfacción y orgullo) en el sentido de una mayor valoración positiva de los adolescentes que no consumen drogas, así como la percepción diferencial del empleo del Castigo-Coerción y de la Reprobación en aquellos otros que experimentan con sustancias psicoactivas en el sentido de reportan ser sometidos a mayores prácticas disciplinares correctivas en las que se recurre a la agresión física y a la violencia psicológica en forma de chantaje emocional y de exacerbación del sentimiento del culpa. 
Tabla 4. Diferencias valorativas en la percepción de la socialización familiar en función del consumo juvenil de drogas (Prueba F, Anova de un factor).

\begin{tabular}{|lccccccc|}
\hline \multirow{2}{*}{\begin{tabular}{l}
\multirow{2}{*}{ FOCIALIZACIÓN } \\
FAMILIAR
\end{tabular}} & Tabaco & Alcohol & Cannabis & Heroína & Cocaína & Anfetaminas & Pegamento \\
\hline Apoyo & $11.899 *$ & $21.650^{*}$ & $10.355^{*}$ & $21.650^{*}$ & $10.355^{*}$ & $2.714^{* *}$ & $2.049 * *$ \\
Castigo-Coerción & $20.455^{*}$ & $12.599 *$ & $5.236^{*}$ & $12.599^{*}$ & $5.326^{*}$ & $3.742 * *$ & $2.935^{* *}$ \\
Sobreprotección & .112 & .001 & .168 & .001 & .235 & .343 & 1.584 \\
Reprobación & $5.855^{*}$ & $7.163^{*}$ & .167 & $7.623^{*}$ & .178 & 1.780 & .435 \\
\hline
\end{tabular}

$* \mathrm{p}<.001,{ }^{* *} \mathrm{p}<.01$

Finalmente, se ha procedido al análisis de la influencia de los estilos disciplinares paternos y las manifestaciones de apoyo o castigo en vínculos interactivos paterno-filiales y de su influencia sobre las actitudes hacia el consumo de sustancias psicoactivas de sus hijos adolescentes en función de tales dinámicas. De acuerdo con los resultados expuestos en la Tabla 5, relativo a las diferencias halladas empleando como variable criterio ya sea el apoyo como factor de protección o la conflictividad familiar como factor de riesgo, se confirma la existencia de diferencias significativas en los indicadores de actitud hacia el consumo bajo una triple dimensionalidad de índole cognitivo, afectivo y comportamental (AICA.FACTOR1-AICA.FACTOR7) e incidiendo en la dimensión relativa a la disposición para el consumo (ACTITUD.FACTOR1-ACTITUD.FACTOR5). En concreto, en los niveles indicativos de alto apego familiar se obtienen puntuaciones medias más elevadas, lo cual denota la manifestación de unas actitudes globales hacia el consumo de drogas de mayor resistencia, así como actitudes de rechazo de invitaciones para el consumo de drogas iniciáticas como alcohol y tabaco y de otras sustancias psicoactivas, una mayor concienciación ante los efectos negativos derivados de las experimentaciones y percepciones valorativas diferenciales vinculadas al desarrollo de una mayor identificación con quienes no son consumidores de sustancias psicoativas. Asimismo, a partir del análisis de otros de los indicadores de disposiciones para el consumo se confirma la existencia de diferencias significativas en el sentido predicho, esto es, se obtienen puntuaciones medias más bajas en evaluación de las disposiciones para experimentar y habituarse a las drogas (ACTITUD.FACTOR1) y al alcohol (ACTITUD.FACTOR2), así como más elevadas en las actitud de resistencia frente al consumo de alcohol (ACTITUD.FACTOR3) y en el grado de acuerdo mostrado con el posible abandono de ambientes y compañías incitadores al consumo (ACTITUD. FACTOR5), lo cual confirma la tendencia actitudinal predicha, en virtud de la cual podría considerarse el Apego familiar como un factor de protección y el Castigo, el Sobrecontrol y la Reprobación como factores de riesgo en el plano actitudinal ante la experimentación con drogas por parte de hijos adolescentes que participan de semejantes vínculos en el ambiente familiar.

Resultados similares a los anteriores pero en la dirección contraria son los hallados a partir del análisis de las percepciones valorativas diferenciales de las actitudes hacia el consumo de adolescentes cuyos padres recurren al castigo (Factor Castigo-Coerción) como medida coercitiva. En aquellos hijos a los que se les somete a semejante estilo disciplinar se constata la manifestación de diferencias significativas en el plano actitudinal, de modo que: $a$ ) muestran unas actitudes globales de mayor permisividad hacia el consumo de sustancias psicoactivas, $b$ ) presentan una distorsión valorativa de las consecuencias negativas derivadas de las experimentaciones con indicadores de menor concienciación y c) su actitud de resistencia frente a una invitación para el consumo de alcohol, tabaco u otras drogas está debilitada en comparación con aquellos que no están sometidos a esos patrones disciplinares en los que se recurre a la agresión física y donde se emplea violencia psicológica en forma de chantaje emocional y exacerbación del sentimiento del culpa. 
Asimismo, se ha constatado que del empleo de la Sobreprotección y control familiar (Factor 3), así como de la Reprobación (Factor 4) se derivan diferencias significativas sobre las actitudes hacia el consumo de sustancias psicoactivas por parte de sus hijos adolescentes. Mediante el recurso a la primera, como actividad de regulación concreta de las pautas interactivas paterno-filiales a la que se ven sometidos los hijos debido a la imposición de normas mediante las que se ejerce un excesivo control de las actividades de los adolescentes se confirma unas actitudes globales menos permisivas, una mayor concienciación ante los efectos negativos y actitud contraria al consumo de drogas (AICA.FACTOR1), una actitud de resistencia al consumo de drogas (AICA.FACTOR2), una mayor rechazo de la invitación al consumo de alcohol (AICA.FACTOR4) y una mayor admiración ante no-usuarios de drogas institucionalizadas (AICA-FACTOR7), así como una menor disposición para experimentar y habituarse a las drogas (ACTITUD.FACTOR5). En el caso del empleo de la reprobación paterna y el recurso manifiesto a tácticas de disciplinares coercitivas se confirman diferencias significativas en la esfera actitudinal hacia el consumo de drogas en sus hijos sometidos a semejantes prácticas disciplinares en indicadores de actitudes globales de mayor permisividad y menor sensibilización frente a la problemática.

Tabla 5. Efectos diferenciales sobre las actitudes hacia el consumo de drogas en función de la socialización familiar (Apoyo, Castigo-Coerción, Sobreprotección-Control, Reprobación).

\begin{tabular}{|c|c|c|c|c|}
\hline ACTITUDES CONSUMO & Ароуо. & $\begin{array}{l}\text { Castigo- } \\
\text { Coerción }\end{array}$ & $\begin{array}{l}\text { Sobreprotección- } \\
\text { Control }\end{array}$ & Reprobación \\
\hline Actitud global hacia el consumo de alcohol & $1.714^{* *}$ & $1.432 * *$ & $1.629 * *$ & $1.998 * *$ \\
\hline $\begin{array}{l}\text { Concienciación ante los efectos negativos } \\
\text { y Actitud contraria al consumo de drogas }\end{array}$ & $1.610^{* *}$ & $1.686 * *$ & $2.668 *$ & $1.321 * *$ \\
\hline $\begin{array}{l}\text { Actitud de Resistencia al consumo de } \\
\text { drogas }\end{array}$ & $1.808^{*}$ & 1.195 & $1.304 * *$ & 1.110 \\
\hline $\begin{array}{l}\text { Rechazo de invitación de Tabaco y Drogas } \\
\text { Ilegales }\end{array}$ & 1.258 & .433 & 1.309 & .788 \\
\hline Rechazo de invitación de Alcohol & $1.550 * *$ & $1.609 * *$ & $1.899 * *$ & .822 \\
\hline $\begin{array}{l}\text { Concienciación ante los efectos negativos } \\
\text { y Actitud contraria al consumo de drogas } \\
\text { institucionalizadas }\end{array}$ & $1.449 * *$ & $1.372 * *$ & .866 & $1.749 * *$ \\
\hline Drogas e identidad de ser mayor & $1.605 * *$ & 1.172 & 1.033 & .816 \\
\hline $\begin{array}{l}\text { Admiración ante no-usuarios de drogas } \\
\text { institucionalizadas }\end{array}$ & .729 & .855 & $1.340 * *$ & $1.578 * *$ \\
\hline $\begin{array}{l}\text { Disposición para experimentar y habituarse } \\
\text { a las drogas }\end{array}$ & $1.794^{*}$ & $1.752 *$ & $1.495^{* *}$ & $1.877^{*}$ \\
\hline $\begin{array}{l}\text { Disposición para experimentar y habituarse } \\
\text { al alcohol }\end{array}$ & $1.396 * *$ & $1.442 * *$ & .960 & .589 \\
\hline $\begin{array}{l}\text { Actitud de Resistencia frente al consumo } \\
\text { de alcohol }\end{array}$ & $1.349 * *$ & $1.371^{* *}$ & .814 & .621 \\
\hline $\begin{array}{l}\text { Actitud de Resistencia frente al consumo } \\
\text { de drogas ilegales }\end{array}$ & $1.425^{* *}$ & 1.130 & 1.147 & .657 \\
\hline $\begin{array}{l}\text { Abandono de ambientes y compañías } \\
\text { incitadores }\end{array}$ & 1.209 & $1.323 * *$ & .478 & 1.089 \\
\hline
\end{tabular}

$* \mathrm{p}<.001, * * \mathrm{p}<.01, * * * \mathrm{p}<.05 * * * * \mathrm{p}<.10$ 


\section{Discusión}

A pesar de crisis referenciales y de identidad de las tipologías tradicionales de familia contemporánea y de alusiones a procesos de desinstitucionalización de esta agencia socializadora por excelencia como permanente vital-cultural es origen, mediación y destino de la vida (Borobio, 1998), ha sido definida como red de solidaridad (Ortega, 1996a, b), aparte de ser descrita como la célula social y cultural más significativa (Duch, 1997). Esa derivación hacia familia postmodernas o postnucleares (Burin, 1998; Cheal, 1991; Eguiluz, 2008; Flaquer, 1999; Fuks, 2007; Luengo \& Román, 2005; Rodríguez, 2001; Sánchez-Pardo, 1997) ha inducido cambios en el trato y en los estilos, en sus significados y simbolismos, si bien su referente como baluearte psicoafectivo no se cuestiona por parte de los propios implicados. En este sentido, la percepción valorativa de los adolescentes de sus vínculos afectivos con sus padres, si bien está mediatizada por multitud de factores intervinientes que la modulan, en esencia se ha demostrado en este estudio que en general es positiva, habiéndose hallado un amplio consenso en empleo de adecuados mecanismos de regulación y control emocional, ofrecimiento de apoyo con manifestaciones recíprocas de cariño, búsquedas de ayuda y comprensión, muestras de respeto, satisfacción y orgullo, afecto y complicidad, identificaciones referenciales, etc. En el sentido opuesto, se han obtenido bajos porcentajes de acuerdo alusivos a indicadores de problemas en la comunicación paterno-filial, disconformidad con el empleo de medidas disciplinarias ejemplarizantes u otras coercitivas o desaprobaciones paternas de las identidades de sus hijos adolescentes. Similar tendencia de respuesta se obtiene al evaluar la Sobreprotección y el Control paternos, constatándose su implicación en labores de supervisión del rendimiento académico de sus hijos adolescentes y manifestando un excesivo control en comparación con los de otros compañeros, en opinión de sus hijos adolescentes. Ante los indicadores de Reprobación como seña identificativa de unas conductas de desaprobación paterna de las conductas de sus hijos, éstos informan de un puntual empleo del chantaje emocional medido bajo la elicitación del sentimiento de decepción paterna ante la realización de una falta, así como de una escasa tendencia inductora a la auto-inculpación del desasosiego paterno y proyecciones del sentimiento de culpa.

Tales cambios descritos en la percepción valorativa de los afectos y de los mecanismos disciplinates empleados en el seno familiar en las relaciones paterno-filiales varían en función de los niveles de edad de los adolescentes, de modo que a medida que aumenta la edad surgen sentimientos de conflicto junto a percepciones de sobreprotección y controles impositivos varios (Moreno et al., 2000; Moral \& Ovejero, 1998a), si bien la comunicación fluida y el apoyo percibido de los padres representan factores de protección asociados a los estilos de vida saludables a cualquier edad (Rodrigo, Máiquez, Mendoza, Rubio, Martínez \& Martín, 2004).

Aplicado lo anterior a la problemática de la experimentación con drogas se confirma el efecto del modelado paterno sobre el consumo de sus hijos adolescentes, de modo que se han analizado las experiencias paternas con las sustancias psicoactivas, así como la percepción del riesgo inherente a tales consumos. Un clima afectivo conflictuado, así como una baja percepción valorativa de los vínculos, desajustes comunicativos y un bajo grado de interacción y de apoyo por parte de los padres, entre otras variables, se asocian al consumo de drogas (Álvarez et al., 1999; Donovan et al., 1990; García-Pindado, 1992; Graña \& Muñoz, 2000; Pérez \& Mejía, 1998; Spoth, Redmind \& Lepper, 1999; Vielva, 2001). Asimismo, las experiencias paternas con las drogas han sido objeto de análisis bajo la premisa de que tales conductas de consumo pueden ser un reflejo más del tipo de realidad habitual de intento de resolución de conflictos, modelo de afrontamiento y manejo de tensión que se apoya, e incluso se fundamenta abiertamente, en el uso de fármacos y drogas, y que se proyecta en cada uno de nosotros, siendo esto claramente aplicable a sus propios hijos. De este modo, en su conjunto, se confirma que los padres son consumidores de tabaco (86.7\%) y alcohol (69.3\%), porcentajes que se reducen significativamente respecto a la experimentación con otras drogas (tales como cannabis, anfetaminas, somníferos, pegamento, heroína y cocaína) en las que al analizar las experiencias paternas con tales sustancias psicoactivas se confirman usos residuales. Atendiendo a la interpretación de los encuestados, se confirma una distorsión de la percepción de riesgo inherente a tales experimentaciones ya que un elevado porcentaje considera que se derivan consecuencias 
buenas del uso de ciertas drogas tales como el tabaco (44.7\%) o el alcohol (28.2\%), lo cual podría ser un inequívoco indicador de la mentalidad del usuario en virtud de la cual se distorsionan las percepciones de riesgo inherentes a la experimentación (Echeburúa \& Del Corral, 1988).

Se ha confirmado el hallazgo bien establecido en la literatura sobre el tema en relación a la influencia ejercida por las experiencias paternas con las drogas sobre las actitudes hacia el consumo de sus hijos (Barca et al., 1996; Espada et al., 2008; Jennison \& Johnson, 2001; Méndez \& Espada, 1999; Moral et al., 2004). En concreto, en aquellos núcleos familiares en los que los padres experimentan con tales sustancias sus hijos manifiestan un patrón actitudinal de mayor permisividad y de menor concienciación ante los efectos negativos derivados de la experimentación, así como la inducción de una percepción valorativa distorsionada de los riesgos y la evidencia de ilusiones de invulnerabilidad. Se confirma que el modelado paterno representa un factor de riesgo sobre la inclinación para el consumo y las propias experiencias de experimentación con drogas, en función de las experiencias paternas con las drogas.

En la literatura sobre el tema, cuyas principales referencias se han explicitado en la exposición teórica (Averna \& Hesselbrock, 2001; Espada et al., 2008; Graña \& Muñoz-Rivas, 2000; Martínez \& Robles, 2001; Moral, 2007), se determinaba que el apoyo familiar actúa como factor de protección ante la posible experimentación con sustancias psicoactivas de sus hijos adolescentes. Esta tendencia se ha corroborado en nuestro estudio, obteniéndose en los niveles indicativos de alto apego familiar puntuaciones medias denotativas de unas actitudes globales hacia el consumo de drogas de mayor resistencia (rechazo de invitaciones para el consumo de drogas iniciáticas como alcohol y tabaco y de otras drogas, mayor concienciación ante los efectos negativos, menores disposiciones para experimentar y habituarse a las drogas y evitación de situaciones de riesgo). En cambio, se confirma la inducción de un estilo disciplinar severo a la manifestación de unas actitudes globales de mayor permisividad, así como una percepción distorsionada de los riesgos inherentes a los usos. Asimismo, se ha constatado el escaso efecto derivado del empleo de la sobreprotección y control familiar, así como de la reprobación paterna sobre las actitudes hacia el consumo.

Como líneas prospectivas de actuación respecto a la intervención en materia de drogas se propone aunar esfuerzos en propuestas optimizadoras de recursos personales, de mejora de las relaciones paterno-filiales y de afrontamiento de las presiones grupales. A nivel preventivo se ha constatado la eficacia del enfoque de habilidades de resistencia social y, en concreto, de programas de entrenamiento en habilidades para la vida calificadas así por organismos internacionales tales como la OMS (1993), dada la escasa acción de los programas basados en la didáctica formativa en modificar conductas de consumo (Botvin \& Kantor, 2000; Moral et al., 2009; Toumbourou \& Stockwell, 2007). Entre ellos, destacan los programas que entrenan las habilidades de resistencia a la presión del grupo de pares (Botvin \& Griffin, 2005; De Vries et al., 2006; Faggiano, Vigna-Taglianti, Versino, Zambon, Borracino \& Lemma, 2008; Griffin, Botvin, Nichols \& Doyle, 2003; Griffin, Botvin \& Nichols, 2006). Asimismo, se ha confirmado la eficacia de programas dirigidos a fomentar en los padres una crianza adecuada que redunden en la mejora de sus habilidades parentales y el comportamiento de sus hijos (Kumpfer, 2004).

Se aboga por la demanda de una intervención psicosocial contextual, que complemente a la educativa-preventiva en las aulas y a la educación primaria en la familia, lo cual representa una solicitud no sólo lícita, sino obligada. El miembro individual es lo que es por su vinculación al cuerpo social. Lo social precede a lo individual, siendo al principio la comunidad como instancia constitutiva y producto singular del tejido social (Blanco, 1988). Precisamente, por la interrelación entre simbolismos, significados, prácticas, convenciones, dinámicas contextuales, historicidades, etc., es como se ha ido (re)conformando, de modo que resultaría contrapreventivo cualquier otro tipo de actuación que desvinculase al usuario, de la sustancia y del contexto en sí mismo. De este modo, hacer un análisis exhaustivo de la frecuencia, modalidad, etc. de consumo, así como del tipo de conocimiento sobre las drogas, las actitudes permisivas o no, los factores etiológicos, la detección de individuos que consuman, la comprensión del fenómeno y su relación directa con la propia comunidad, entre otros, serían los objetivos válidos de un programa de prevención, aunque ello no se agota en este tipo de medidas que han de verse comple- 
mentadas con otras labores que se podrían denominar, a nivel expositivo, propiamente de intervención tales como las relativas a la sensibilización o concienciación personal, intentos de promover cambios estructurales, implicaciones comunitarias, pedagogía del ocio y alternativas de tiempo libre, etc.

En virtud de lo expuesto, desde las principales líneas de intervención en materia de drogas se ha de incidir en la implicación activa de la familia y del grupo de pares, así como en la colaboración de otros agentes (escuela, asociación, comunidad, etc.), aunándose apoyos en distintos escenarios familiares, socioeducativos y comunitarios.

\section{Referencias}

Alberdi, I. (1999) La nueva familia española. Madrid: Taurus.

Alvarez, Y., Palacios, F.A. \& Fuertes, J.C. (1999). Adolescentes y drogas para padres que no quieren ser los últimos en enterarse. Madrid.

Andrade, P., Pérez, C., Alfaro, L.B., Sánchez, M.E. \& López, A. (2009). Resistencia a la presión de pares y pareja y consumo de tabaco y alcohol en adolescentes. Adicciones, 21 (3), 243-250.

Averna, S. \& Hesselbrock, V. (2001). La relación entre apoyo social percibido y consumo de drogas en hijos de alcohólicos. Addictive Behaviors, 26 (3), 363-374.

Barca, A., Otero, J.L., Mirón, L. \& Santorium, R. (1996). Determinantes familiares, escolares y grupales del consumo de drogas en la adolescencia. Implicaciones para el tratamiento. Estudios de Psicología, 25, 1-15.

Barnea, Z., Teichman, M. \& Rahav, G. (1992). Personality, cognitive, and interpersonal factors in adolescent substance use: a longitudinal test of an integrative model. Journal of Early Adolescence, 11, 56-95.

Blanco, A. (1988). La psicología comunitaria, ¿una nueva utopía para final del siglo XX? En A. Martín, F. Chacón \& M. Martínez. Psicología Comunitaria (pp. 11-33). Madrid: Visor.

Borobio, D. (1998). Políticas familiares y cultura. En D. Borobio (Coord.). Familia y cultura. La Familia en el umbral del año 2000 (pp. 151-180). Salamanca: Publicaciones de la Universidad Pontificia de Salamanca.

Botvin, G., \& Kantor, L (2000). Preventing alcohol and tobacco use through life skills training theory, methods and empirical finding. Alcohol Research and Health, 24, 250-257.

Burin, M. (1998). La relación entre padres e hijos adolescentes. En M. Burin \& I. Meler. Género y familia. Poder, amor y sexualidad en la construcción de la subjetividad (pp. 193-210). Barcelona: Paidós.

Cabrillo, F. (2004). La nueva familia española: un análisis económico. Papeles de Economía Española, 100 (2), 92-101.

Calleja, N., \& Aguilar, J. (2008). Por qué fuman las adolescentes: Un modelo estructural de la intención de fumar. Adicciones, 20, 387-394.

Castellana, M. \& Lladó, M. (1999). Adolescencia y juventud: Prevención y percepción del riesgo al consumo. Revista Española de Drogodependencias, 24, 118-130.

Cheal, D. (1991). Family and the State of Theory. New York: Harverster Wheatsheaf.

Charro, B. \& Martínez Díaz, M.P. (1995). Dinámica personal y familiar de los toxicómanos. Madrid: Publicaciones de la Universidad Pontificia Comillas.

De Vries, H., Dijk, F., Wetzels, J., Mudde, A., Kremers, S., Ariza, C., et al. (2006). The European Smoking Prevention Framework Approach (ESFA): Effects after 24 and 30 months. Health Education Research, 21, 116-132. 
DiClemente, R.J., Wingood, G.M., Crosby, R., Sionean, C., Cobb, B.K., Harrington, N, K., Davies, S., Hook, E. \& Ob, M.K. (2001). Parental monitoring: association with adolescents' risk behaviors. Pediatrics, 107, 1363-1368.

Donovan, J.E., Jessor, R. \& Costa, F.M. (1990). Adolescent health behavior and conventionalityunconventionality: an extension of problem-behavior theory. Behavior 10 (1), 52-61.

Duch, LL. (1997). La educación y la crisis de la modernidad. Barcelona: Paidós.

Echeburúa, E. \& De Corral, P. (1988). Evaluación y tratamiento de un caso clínico de alcoholismo. En D. Macià \& F.X. Méndez. Aplicaciones clínicas de la evaluación y modificación de conducta. Estudio de Casos (pp. 147-207). Madrid: Pirámide.

Eguiluz, L. (2008). La familia postmoderna. Congreso Internacional de Psicología. México.

Epstein, J., Bang, H. \& Botvin, G. (2007). Which psychosocial factors moderate or directly affect substance use inner-city adolescents? Addictive Behaviors, 32, 700-730.

Epstein, J. \& Botvin, G. (2008). Media resistance skills and drug skill refusal techniques: What is their relationship with alcohol use among inner-city adolescents? Addictive Behaviours, 33, 528-

537.

Epstein, J., Zhou, X., Bang, H. \& Botvin, G. (2007). Do Competence Skills Social Benefits of Drinking on Alcohol Use Among Inner-City Adolescents? Preventive Science, 8, 65-73.

Escámez, J. (Ed.). (1997). Prevención de la drogadicción. Valencia: Nau Llibres.

Espada, J.P., Pereira, J.R. \& García-Fernández, J.M. (2008). Influencia de los modelos sociales en el consumo de alcohol de los adolescentes. Psicothema, 20 (4), 531-537.

EUROSTAT (2000). Encuesta de fuerza de trabajo. Luxemburgo: Comisión Europea.

Faggiano, F., Vigna-Taglianti, F., Versino, E., Zambon, A., Borracino, A. \& Lemma, P. (2008). School-based prevention for illicit drugs use: A systematic review 2008. Preventive Medicine, 232-246.

Flaquer, L. (1999). La familia en la sociedad del siglo XXI. Papers de la Fundació, 117, 1-21.

Fuks, I. (2007). La relación de pareja como organización social: desafíos y oportunidades. Sistemas Familiares, 11 (1), 21-34.

García-Pindado, G. (1992). Determinantes familiares del consumo adolescente de droga. Factores ambientales y genéticos, Psiquis, 10, 413-422.

González, P. (2000). Jóvenes españoles 2000. Madrid: Acento.

González-Anleo, J. (1999). Familia y escuela en la socialización de los jóvenes españoles. En J. Elzo, F.A. Orizo, J. González-Anleo, P. González Blasco, M.T. Laespada \& L. Salazar. Jóvenes españoles’99 (pp. 121-182). Madrid: Fundación Santa María.

Graña, J.L. \& Muñoz, M.J. (2000). Factores de riesgo relacionados con la influencia del grupo de iguales para el consumo de drogas en adolescentes. Psicología Conductual, 8, 19-32.

Griffin, K., Botvin, G., Nichols, T. \& Doyle, M. (2003). Effectiveness of a universal drug abuse prevention program for youth at risk for substance abuse initiation. Prevention Medicine, 36, $1-7$.

Griffin, K., Botvin, G. \& Nichols, T. (2006). Effects of a school drug abuse prevention program for adolescents on HIV risk behaviors in young adulthood. Prevention Science, 7, 103-112.

Herrero, J. B. (1992). Comunicación familiar y estilos de socialización familiar. Tesis de Licenciatura. Universitat de Vàlencia. 
Herrero, M.N. (2003). Adolescencia, grupo de iguales, consume de drogas y otras conductas problemáticas. Revista de Estudios de Juventud, 62, 81-91.

Instituto de Política Familiar (2008). Evolución de la familia en España 2007. Madrid: Instituto de Política Familiar.

Jennison, K.M. \& Johnson, K.A. (2001). Alcoholismo paterno como factor de riesgo para el diagnóstico de abuso y dependencia alcohólica según el DSM-IV en mujeres americanas: La protección de la cohesión diádica en la comunicación conyugal. American Journal of Drug \& Alcohol Abuse, 27 (2), 349-374.

Jiménez-Muro, A., Beamonte, A., Marqueta, A., Gargallo, P. \& Nerín, I. (2009). Consumo de drogas en estudiantes universitarios de primer curso. Adicciones, 21, 21-28.

Kloep, M., Hendry, L.B., Ingebrigtsen, J.E., Glendinning, A. \& Espness, G.A. (2001). Young people in 'drinking' societies? Norwegian, Scottish and Swesich adolescents' perception of alcohol use. Health Education Research, 16 (3), 279-291.

Luengo, T. \& Román, J.M. (2005). Familia postmoderna. En J. Romay, R.A. García Mira \& J.E. Real (Eds.). Psicología Social y problemas sociales. Psicología Ambiental, Comunitaria y de la Educación (pp. 581-588). Madrid: Biblioteca Nueva.

Kumpfer, K.L. (2004). Effectiveness of familiy focused interventions for school-based prevention. En K. E. Robinson (Ed.): Advances in schoolbased mental health interventions: Best practices and program models. Kingston, NJ, US: Civic Research Institute.

Macià, D. (1986). Cuestionario de Actitudes acerca del alcohol y Cuestionario de Información. Método Conductual de Prevención de Drogodependencias. Valencia: Promolibro.

Macià, D., Olivares, J. y Méndez, F.X. (1993). Intervención psicológica. Programas aplicados de tratamiento. Madrid: Pirámide.

Martínez, J.M. \& Robles, L. (2001). Variables de protección ante el consumo de alcohol y tabaco en adolescentes. Psicothema, 13, 222-228.

Martínez, J.L., Fuertes, A., Ramos, M. \& Hernández, A. (2003). Consumo de drogas en la adolescencia: importancia del afecto y la supervisión parental. Psicothema, 15 (2), 161-166.

Méndez, F.X. \& Espada, J.P. (1999). Papel de la familia en el inicio del consumo de alcohol. IV Congreso Iberoamericano de Psicología de la Salud. Granada.

Moreno, M., Vacas, C. \& Roa, J.M. (2000). Relaciones entre situación familiar, clima social y adaptación en adolescentes. Boletín de Psicología, 68, 75-88.

Moral, M.V. (2007). Personalidad, resiliencia y otros factores psicosociales asociados al consumo de sustancias psicoactivas en la adolescencia: propuesta etiológica. Monografía Personalidad y consumo de drogas. Revista Española de Drogodependencias, 32 (3), 250-291.

Moral, M.V. \& Ovejero, A. (1998a). El enfrentamiento generacional entre adolescentes y padres como profecía no del todo autocumplida: ¿Convivencia o coexistencia?. Intervención psicológica en la adolescencia, Vol. II (pp. 470-478). Pamplona: Secretaría Técnica del VIII Congreso INFAD. Departamento de Psicología y Pedagogía de la Universidad Pública de Navarra.

Moral, M.V. \& Ovejero, A. (1998b). Calidad del ser joven y cantidad de sustancias psicoactivas. II Congreso Iberoamericano de Psicología de la Salud. Madrid.

Moral, M.V. \& Ovejero, A. (2003). Actitudes ante el consumo de sustancias psicoactivas y mentalidades del usuario en adolescentes de Secundaria. Entemu, XV, 151-175.

Moral, M.V. \& Ovejero, A. (2005a). Modificación de las actitudes, los hábitos y frecuencia de consumo de alcohol y otras sustancias psicoactivas en adolescentes españoles a partir de un programa educativo-preventivo. Revista Colombiana de Psicología, 14, 100-118. 
Moral, M.V. \& Ovejero, A. (2005b). Análisis diferencial por niveles de edad de las actitudes hacia el consumo de sustancias psicoactivas en adolescentes españoles. Interamerican Journal of Psycholog, 39 (3), 325-338.

Moral, M.V., Ovejero, A. \& Pastor, A. (2004). Modelado familiar y del grupo de iguales sobre la experimentación juvenil con sustancias psicoactivas. Boletín de Psicología, 81, 33-68.

Moral, M.V., Ovejero, A., Sirvent, C., Rodríguez, F.J. \& Pastor, J. (2009). Efectos diferenciales sobre las actitudes ante la experimentación con alcohol y la percepción de riesgo en adolescentes españoles consumidores de cannabis y alcohol. Salud Mental, 32 (2), 125-138.

Motrico, E., Fuentes, M.J. \& Bersabé, R. (2001). Discrepancias en la percepción de los conflictos entre padres e hijos/as a lo largo de la adolescencia. Anales de Psicología, 17 (1), 1-14.

Muñoz-Rivas, M.J. \& Graña, J.L. (2001). Factores familiares de riesgo y de protección para el consumo de drogas en adolescentes. Psicothema, 13 (1), 87-94.

Musitu, G. \& García, J.F. (2004). Consecuencias de la socialización familiar en la cultura española. Psicothema, 16 (2), 288-293.

Navarro, L. (2006). Modelos ideales de familia en la sociedad española. Revista Internacional de Sociología, 64 (43), 95-117.

Novacek, J., Raskin, R. \& Hogan, R. (1991). Why Do Adolescent Use Drugs? Age, Sex, and User Differences. Journal of Youth and Adolescence, 20 (5), 475-492.

Olmedo, M., del Barrio, M.V. \& Santed, M.A. (2000). Valoración de padres y maestros de las emociones negativas en la adolescencia: Concordancia de fuentes y percepción de cambio. Revista de Psicología General y Aplicada, 53 (4), 717-732.

Organización Mundial de la Salud (OMS) (1993). Enseñanza en los colegios de las habilidades para vivir. Ginebra: Organización Mundial de la Salud.

Ortega, F. (1996a). Socialización, personalidad y reproducción social. En F. Ortega. Fundamentos de Sociología (pp. 109-132). Madrid: Síntesis.

Ortega, F. (1996b). Los grupos sociales. En F. Ortega. Fundamentos de Sociología (pp. 133-160). Madrid: Síntesis.

Pascual, F. (2002). Percepción del alcohol entre los jóvenes. Adicciones, 14, suplemento 1, 123132.

Pérez, A. \& Mejía, I.E. (1998). Patrones de interacción de familias en las que no hay consumidores de sustancias psicoactivas. Adicciones, 10, 111-119.

Perris, C., Jaconbon, L., Lindström, H., von Knorring, L. \& Perris, H. (1980). Development of a new inventory for assessing memories of parental rearing behaviour. Acta Psychiatric Scandinavian, 61 (265-274).

Pons, J. (1994). Factores de riesgo asociados al consumo abusivo de alcohol en la adolescencia. Tesis Doctoral. Universitat de Vàlencia.

Pons, J. \& Berjano, E. (1997). Análisis de los estilos parentales de socialización asociados al abuso de alcohol en adolescentes. Psicothema, 9(3), 609-617.

Rodríguez, A. (2001). La familia postmoderna: distancia y compromiso. Redes, 18, 103-115.

Rodrigo, M.J., Máiquez, M.L., Mendoza, M., Rubio, R., Martínez, A. \& Martín, J.C. (2004). Relaciones padres-hijos y estilos de vida en la adolescencia. Psicothema, 16 (2), 203-210.

Rodrigo, M.J., Máiquez, M.J., Padrón, I. \& García, M. (2009). ¿Por qué y con qué intención lo hizo? Atribuciones de los padres y adolescentes en los conflictos familiares. Psicothema, 21 (2), 268-273. 
Rodríguez-Martos, A. (1996). Factores de riesgo. Prevención. Detección e intervención en problemas de alcohol en la población infanto-juvenil. En E. Gil, T. Robledo, J. Rubio \& I. Espiga. Alcohol y Juventud 1995 (pp. 61-86). Madrid: Ministerio de Sanidad y Consumo. Centro de Publicaciones de la Secretaría General Técnica.

Sánchez-Pardo (1997). Malestar en la familia: nuevas filiaciones en las narrativas del fin de siglo. Revista de Occidente, 199, 154-173.

Santacreu, J. \& Froján, M.X. (1994). Evaluación del consumo de drogas. En R. FernándezBallesteros. Evaluación conductual hoy. Un enfoque para el cambio en psicología clínica y de la salud (pp. 571-612). Madrid: Pirámide.

Sirvent, C., Moral, M.V.\& Rodríguez, F.J.(2007). Jóvenes \& Alcohol: Conjunto didáctico-audiovisual para educadores, psicólogos, padres y colectivos mediadores. Valencia: Nau Llibres.

Spoth, R., Redmond, C. \& Lepper, H. (1999). Alcohol iniciation outcomes of universal familyfocused preventive intervention: one-and two-year follow-ups of a controlled study. Journal of Studies on Alcohol, 13 Supplement, 103-111.

Sussman, S. (1995). Prevención del consumo de tabaco en niños/as y adolescentes. Psicología Conductual, 3 (3), 283-314.

Tarter, R.E., Schultz, K., Kirisci, L. \& Dunn, M. (2001). ¿Aumenta el riesgo de abuso de drogas de los hijos varones la convivencia con un padre que abusa de drogas? Impacto sobre los factores de vulnerabilidad del individuo, la familia, la escuela y los compañeros. Journal of Child \& Adolescent Substance Abuse, 10 (3), 59-70.

Toumbourou, J. \& Stockwell, T. (2007). Interventions to reduce harm associated with adolescent substance use. Adolescent Health, 4, 1-11.

Vielva, I. (2001). La disciplina y las prácticas educativas. En I. Vielva, L. Pantoja \& J.A. Abeijón. Instituto Deusto de Drogodependencias. Las familias y sus adolescentes ante las drogas. El funcionamiento de la familia con los hijos de comportamiento no problemático, consumidores y no consumidores de drogas (pp. 101-149). Bilbao: Universidad de Deusto. 